\title{
Nitrogen starvation in marine Synechococcus strains: clonal differences in phycobiliprotein breakdown and energy coupling
}

\author{
Todd M. Kana, Nancy L. Feiwel ${ }^{*}$, Laura C. Flynn** \\ Horn Point Environmental Laboratories, University of Maryland, PO Box 775, Cambridge, Maryland 21613, USA
}

\begin{abstract}
The effect of nitrogen starvation on photosynthetic pigments and energy coupling was compared in Synechococcus sp. (Cyanophyta) strains originating from oceanic (oligotrophic) or coastal (eutrophic) marine environments. A survey indicated that those of oceanic or subtropical origin retained a greater fraction ( 55 to $98 \%$ ) of their major phycobiliprotein during a 24 h nitrogen starvation period compared to coastal strains $(30$ to $44 \%)$. For 3 strains studied in detail, nitrogen starvation caused a significant ( $>85 \%$ ) loss of phycoerythrin from Synechococcus sp. WH8018 after 24 h, but only a minor loss (<25\%) from Synechococcus sp. WH7803 or WH8103 after 3 d starvation. All 3 strains exhibited reduced gross oxygen evolution during the first $24 \mathrm{~h}$ of starvation, however, indicating a reduction in energy transfer from phycoerythrin to the electron transport chain. Changes during starvation in the in vivo fluorescence excitation and emission spectra indicated a small degree of uncoupling of phycoerythrin from allophycocyanin in Synechococcus sp. WH7803 and WH8103 but not Synechococcus sp. WH8018. In neither case could it account for the measured loss in photosynthetic efficiency, however. The unusual nature of phycobiliprotein regulation in oceanic strains may reflect an adaptation to episodic (few days time scale) inputs of limiting nutrients to oligotrophic surface waters, thus providing a mechanism for more rapid rejuvenation.
\end{abstract}

\section{INTRODUCTION}

Removal of nitrogen from the growth media of cyanobacteria generally causes 'chlorosis' (Allen \& Smith 1969) due to a drastic reduction in phycobiliproteins (PBPs). The phenomenon is fairly rapid with typically 80 to $95 \%$ of the PBPs degraded during the first $24 \mathrm{~h}$ of starvation (Allen \& Hutchison 1980, Boussiba \& Richmond 1980). Pigmentation loss is also specific to PBPS due to a proteinase that is activated during the initial stages of starvation (Foulds \& Carr 1977. Wood \& Haselkorn 1980). The fate of the brokendown PBPs appears to be the synthesis of new proteins since total cellular protein remains constant (Allen \& Hutchison 1980, Boussiba \& Richmond 1980). A number of studies have emphasized the role of PBP

\footnotetext{
Present addresses:

- 2798 Riverside Dr., Wantagh, New York 11793, USA

-Washington College, Chestertown, Maryland 21620, USA
}

degradation in supporting growth during nitrogen starvation and have concluded that PBP, in addition to being a photosynthetic accessory pigment, has a functional role as a nitrogen storage compound (reviewed by Carr 1988).

Relatively little emphasis has been placed on the effect of nitrogen starvation on photosynthesis, despite the direct impact of PBP losses on light harvesting. Moreover, because the essence of a starvation process is to force a cell into unbalanced growth with respect to the acquisition of essential nutrients and energy inputs and outputs, principal physiological adaptations should involve mechanisms that alleviate those imbalances. In a simple analysis, one would predict a decrease in photosynthetic output, as has been previously observed (Boussiba \& Richmond 1980, Glibert et al. 1986, Elmarjani \& Herdman 1987, Allen et al. 1990), as the demand for photosynthate diminishes during starvation of an essential nutrient. Under conditions of constant illumination, the photosynthetic apparatus experiences a progressive increase in the ratio of 
(light) energy absorbed to (chemical) energy produced. Thus, the reduction in PBP may also be viewed as an adaptive mechanism to reduce the absorption of light energy when the utilization of photosynthate is restricted (Magnus \& Schindler 1912).

We report here native Synechococcus sp. strains that are unusual in the way they respond to nitrogen starvation. In previous studies it was observed that growth of an oceanic Synechococcus sp. strain (WH7803) responded very rapidly to nitrogen starvation and replenishment compared to a coastal marine strain (Glibert et al. 1986, Glibert \& Ray 1990) or freshwater cyanobacteria species (Allen \& Smith 1969, Allen \& Hutchison 1980). Curiously, the oceanic strain did not show the characteristic chlorosis of nitrogen starved cyanobacteria, suggesting that the PBPs were conserved. The present study was designed to directly investigate PBP changes and address the issue of energy harvesting and utilization in oceanic vs coastal strains. We predicted that energy absorbed by phycoerythrun (PE) in strains that conserved the pigment would have to be dissipated by some mechanism in order to reduce the amount of energy reaching the photosystems as photosynthesis became feedback inhibited. Work of Barlow \& Alberte (1987) suggested that this may be accomplished by an increased fluorescence yield of the PBPs as was shown in Synechococcus sp. WH7803 when exposed to a shift-up in light intensity, a condition that causes a similar imbalance in the flow of energy through the photosynthetic apparatus. Because of the unusual response of Synechococcus sp. WH7803, we surveyed a number of genetically distinct marine Synechococcus sp. strains isolated from oceanic and coastal environments to determine whether there were distinct phenotypes associated with the different habitats.

\section{MATERIALS AND METHODS}

Survey of Synechococcus sp. strains. The effect of nitrogen starvation on PBP concentration was determined in 12 Synechococcus sp. strains obtained from the Woods Hole Culture Collection. Cultures were grown at $23^{\circ} \mathrm{C}$ in exponential phase in $\mathrm{F} / 2$ (Guillard \& Ryther 1962) nutrients (-Cu and vitamins) added to $80 \%$ Caribbean Sea water (30 ppt final salinity) with continuous illumination at 60 to $80 \mu \mathrm{E} \mathrm{m}^{-2} \mathrm{~s}^{-1}$ using cool-white fluorescent lamps. Nitrogen starvation. was initiated by filtering (Nuclepore) and washing cells off the filter into nitrogen-free medium. Cultures were

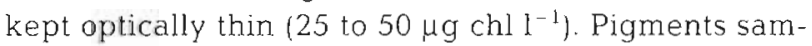
ples were handled as described below, except that the proteinase inhibitors, benzamidine, phenylmethylsulfonyl fluoride, and $\epsilon$-amino caproic acid were added (1 $\mathrm{mM}$ ) to the suspension.
Growth. Synechococcus sp. strains WH.8103, WH.7803, and WH8018 were acclimated to the experimental light and temperature conditions by frequent dilution of batch cultures for $>14 \mathrm{~d}$ prior to experimentation. All cultures were maintained at chl concentrations of $<50 \mu \mathrm{g} \mathrm{l}^{-1}$ to minimize physiological changes due to self-shading. A bank of an equal number of 'cool-white' and 'daylight' fluorescent lamps provided

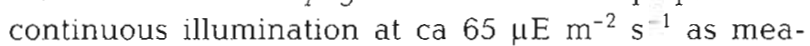
sured by a Biospherical Instruments QSL-100 meter with the spherical $(4 \pi)$ sensor inserted in the center of the $2.4 \mathrm{l}$ polycarbonate bottle containing culture at early stationary phase. Temperature fluctuated between 24 and $27^{\circ} \mathrm{C}$. All cultures were essentially free of bacterial contamination (i.e. bacterial densities were $<10 \%$ of cyanobacterial densities) as determined by microscopic observation of samples stained with acridine orange.

Experiments were initiated by inoculating a flask with exponentially growing cells in a media containing the same $\mathrm{F} / 2$ nutrients except that the initial $\mathrm{NO}_{3}^{-}$concentration was adjusted to ca $60 \mu \mathrm{M}$, which yielded an optically thin culture at stationary phase (ca $60 \mu \mathrm{g} \mathrm{chl}$ $\left.1^{-1}\right)$. Each of the other nutrients were $>10$ times in excess of being limiting. Cultures were continuously bubbled with filtered and humidified air. Cell densities were determined by counting autofluorescent cells using an epifluorescence microscope (Waterbury et al. 1986). The time at which $\mathrm{NO}_{3}^{-}$was exhausted was determined by periodically monitoring for its presence using a colorimetric assay (Strickland \& Parsons 1972). Our estimate of the time of exhaustion (point at which assay produced no visible color) was within $15 \mathrm{~min}$ of the true time.

Photosynthesis measurements. True gross oxygen evolution rates were determined using membrane inlet mass spectrometry and ${ }^{18} \mathrm{O}$ (Radmer \& Ollinger 1980, Kana 1992). Cultures were analyzed either directly or after a 2- or 3-fold concentration step which involved filtration and a wash into filtered growth media from which the cells originated. Samples were analyzed in a custom-built $38 \mathrm{ml}$ acrylic chamber with supported magnetic stir bar and radially mounted silicone membrane (General Electric, MEM-213). The membrane was attached to a vacuum line with a cryogenic trap to remove water vapor and $\mathrm{CO}_{2}$ before the gases of interest entered the mass spectrometer (Balzers QMS-420 controlled with an auxiliary computer and customized software). Signals of masses 28,32 and 36 were detected in a continuous cycle each lasting ca $1 \mathrm{~s}$. Signal to noise ratio was reduced by normalizing the oxygen signals to nitrogen. Leakage was monitored in a preliminary analysis as described below but without cells. 
Each culture sample was bubbled with nitrogen for ca $5 \mathrm{~min}$ to lower the oxygen concentration, injected into the cuvette with a bubble of ${ }^{36} \mathrm{O}_{2}$ from a $>98$ atom-\% enriched source, and stirred until the total oxygen concentration was between 70 and $100 \%$ of saturation. Photosynthesis vs irradiance curves were determined by stepping up the illumination from darkness to ca $1800 \mu \mathrm{E} \mathrm{m}^{-2} \mathrm{~s}^{-1}$ at ca 2 min intervals. Light was provided by a Kodak slide projector and attenuated by glass slides sprayed with black paint or India ink. Light intensity was determined with a Biospherical QSL-100 meter with the probe placed on the proximate surface of the cuvette. Generally 10 or more irradiance levels were tested and initial slopes calculated by linear regression of the first 4 to 6 data points. Standard errors of the slope estimate were $<10 \%$ of the least squares fit.

Pigment determinations. For PBP determinations, cells were harvested by filtration onto polycarbonate filters and washed into $5 \mathrm{ml}$ of $0.05 \mathrm{M}$ phosphate buffer $(\mathrm{pH} 7.0)$, then quickly frozen in liquid nitrogen and stored at $-65{ }^{\circ} \mathrm{C}$ for ca $2 \mathrm{wk}$. Recovery of cells is $>95 \%$ based on the lack of visually detectable pigment on filters after the washing step. PBPs were released from the cells by 3 passes through a French pressure cell at 20000 psi (ca $1.33 \times 10^{8} \mathrm{~Pa}$ ). Samples were then centrifuged at $100000 \times g_{\text {ave }}$ for $1 \mathrm{~h}$ to remove cell debris and membrane bound pigments. Pellets were free of color indicative of PBPs. An absorption spectrum was determined on the supernatant containing the soluble PBP mixture. PE concentration in Synechococcus sp. WH8103 was calculated using the extinction coefficient determined by Ong (1988) for the major form of PE $\left(2.78 \times 10^{6} \mathrm{M}^{-1} \mathrm{~cm}^{-1}\right.$ at $492 \mathrm{~nm}$ for a $240 \mathrm{kDa}$ unit). Extinction coefficients provided by Alberte et al. (1984) were used to calculate PE concentrations in Synechococcus sp. WH7803 $\left(\mathrm{E}_{1 \mathrm{~cm}}^{\%}=105\right.$ at $\left.548 \mathrm{~nm}\right)$ and Synechococcus sp. WH8018 ( $\mathrm{E}_{1 \mathrm{~cm}}^{\% / 6}=80$ at $\left.551 \mathrm{~nm}\right)$. Phycocyanin (PC) and allophycocyanin (AP) concentrations were calculated using the simultaneous equations used by Kursar \& Alberte (1983).

For chl determinations, cells were filtered on Gelman GF/F filters, frozen and stored as above. Chl was extracted in $80 \%$ acetone and analyzed by HPLC (Mantoura \& Llewellyn 1983).

Fluorescence measurements. Changes in energy coupling were determined by measuring room temperature fluorescence excitation and emission spectra using an SLM Aminco SPF-500C spectrofluorometer. Excitation spectra of chl (680 nm) fluorescence were determined in ratio mode. Emission spectra were determined using excitation wavelengths of $495 \mathrm{~nm}$ for Synechococcus sp. WH8103 and WH7803 and $510 \mathrm{~nm}$ for Synechococcus sp. WH8018. Emission spectra were corrected for instrument response using manufacturer- supplied correction factors. A $4 \mathrm{~nm}$ band pass was used for excitation and emission beams.

\section{RESULTS}

\section{Strain survey}

Synechococcus sp. strains were selected to represent both oceanic and coastal origin as well as each of the 4 clusters defined by the ratio of phycourobilin:phycoerythrobilin chromophores on PE (Waterbury et al. 1986). Loss of PE (PC in the case of Synechococcus sp. WH5701) relative to chl was uniformly greater in strains isolated from coastal as opposed to oceanic or tropical marine settings (Table 1) with $>66 \%$ of the major PBP being lost during 24 h of starvation. Strains originating from more oligotrophic sites lost from 2 to $45 \%$ of their PE. The highly conservative strains $(<20 \%$ reduction) were represented in each urobilin grouping, but not in strains which lacked urobilin.

\section{Growth and photosynthesis}

The 3 strains studied in detail grew exponentially while $\mathrm{NO}_{3}^{-}$was detectable in the media (Fig. 1), but stopped either abruptly or soon after the point at

Table 1 Survey of the nitrogen starvation effect on phycoerythrin (PE) or phycocyanin (PC) in different marine Synechococcus spp. strains. Exponential phase cultures were washed and resuspended in nitrogen-free medium and sampled at time 0 and $24 \mathrm{~h}$. PE or PC concentrations were normalized to chlorophyll measured at each time point. Strains categorized as oceanic were isolated from North Atlantic open ocean sites or, in the case of Synechococcus WH8203, a Bermuda harbor. Strains are also categorized according to the presence or relative amount of phycourobilin (PUB) in PE

\begin{tabular}{|llcc|}
\hline Strain & Origin & $\mathrm{A}_{495}: \mathrm{A}_{545}$ & $\begin{array}{c}\text { Fraction of PE } \\
\text { (or PC) remain- } \\
\text { ing after } 24 \mathrm{~h}\end{array}$ \\
\hline SPCC7335 & Intertidal $^{\text {a }}$ & No PUB & 0.30 \\
WH8018 & Coastal & No PUB & 0.32 \\
WH5701 & Coastal & No PE & 0.44 (PC) \\
WH7805 & Oceanic & No PUB & 0.63 \\
WH7803 & Oceanic & 0.39 & 0.83 \\
WH8203 & Oceanic & 0.42 & 0.66 \\
WH8106 & Oceanic & 0.44 & 0.93 \\
WH8002 & Gulf of Mexico & 0.48 & 0.96 \\
WH8020 & Oceanic & 0.78 & 0.55 \\
WH8011 & Oceanic & 0.84 & 0.59 \\
WH8406 & Gulf of Mexico & 0.84 & 0.82 \\
WH8103 & Oceanic & 2.40 & 0.98 \\
& & & \\
'Epiphytic & & & \\
\hline
\end{tabular}




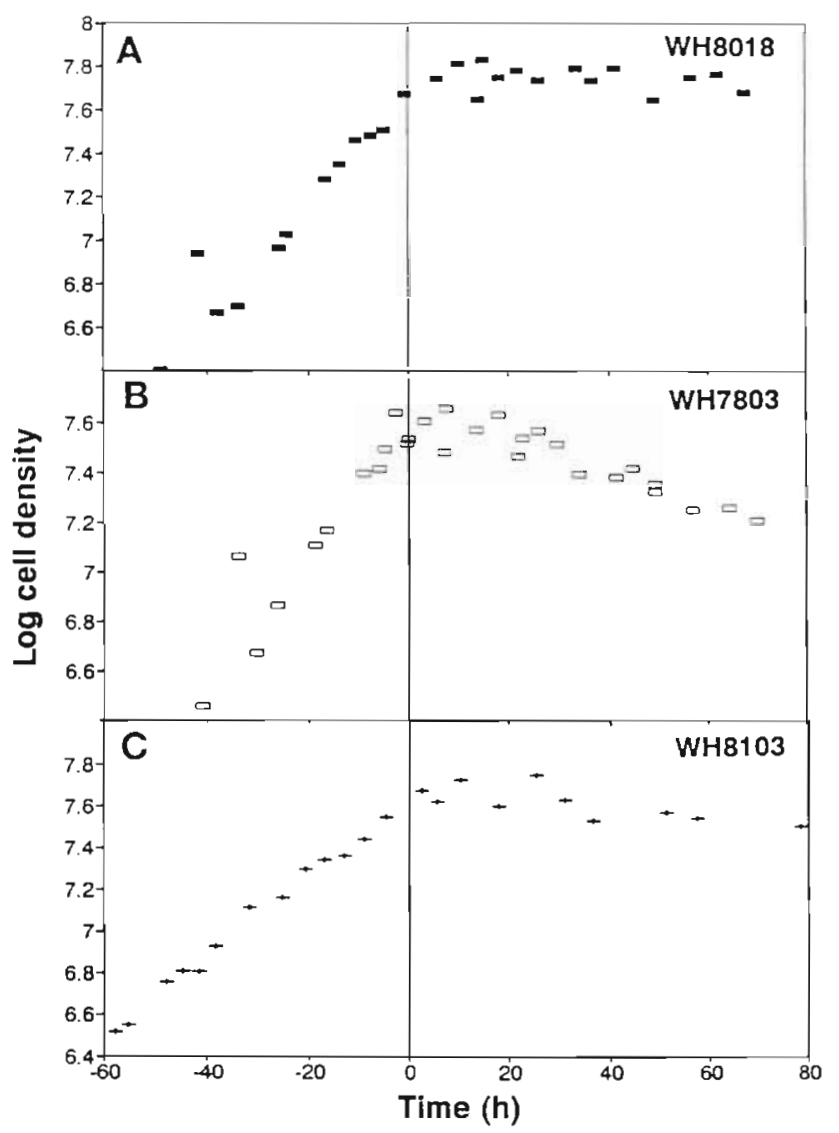

Fig. 1 Comparison of growth measured as cell density of 3 strains of Synechococcus sp. (designated in each panel) subjected to nitrogen-limiting growth media. Time 0 was when nitrate was no longer measurable in the media

which $\mathrm{NO}_{3}^{-}$was exhausted (designated as $t_{0}$ ). Only in Synechococcus sp. WH8018 did cell density increase after time 0 , but only by $30 \%$. This differential sensitivity of growth to the disappearance of nitrate from the media is consistent with previous studies of Synechococcus sp. WH7803 and WH8018 (Glibert et al. 1986, Glibert \& Ray 1990). Celis of Synechococcus sp. WH7803 and to a lesser extent WH8103 became visually brighter under the epifluorescence microscope soon after $t_{0}$ and remained bright throughout the starvation period. In contrast, Synechococcus sp. WH8018 became dimmer and photobleached more rapidly during the period of nitrogen starvation and by the third day were difficult to detect.

Changes in the energy transfer efficiency to PS II were determined by measuring light-limited gross oxygen evolution rates at intervals before and after $t_{0}$. Normalizing the oxygen evolution rate to the photosynthetic pigment concentration gives an indication of the change in apparent quantum yield of that pigment in driving electron transport. In the present case, we are interested in the effectiveness of the PBPs, especially $\mathrm{PE}$. In all 3 strains, we observed a significant $(>60 \%$ ) reduction in $P E$-specific apparent quantum yields during the $3 \mathrm{~d}$ of starvation (Table 2 ) with most of the change occurring by ca $24 \mathrm{~h}$. Synechococcus sp. WH8018 differed from the other 2 strains by exhibiting a more pronounced decline in chl- or cell-specific energy transfer efficiency relative to the decline in PEspecific efficiency (data not shown). This was due to differences between strains in the extent to which various pigments were lost during nitrogen starvation.

\section{Changes in pigment concentrations}

PE accounted for 80 to $90 \%$ of the total PBP in each of the strains. But only Synechococcus sp. WH8018 exhibited a significant effect of nitrogen starvation on the PBP concentration (Table 1). In that strain, PE per cell decreased $75 \%$ during the first $24 \mathrm{~h}$ and $85 \%$ by $72 \mathrm{~h}$. Moreover, PE declined proportionally faster than PC, AP, or chl concentrations indicating a preferential loss of the peripheral components of the phycobilisomes. Chl was conserved, remaining at approximately $3 \mathrm{fg}$ cell $^{-1}$ during the entire starvation period. By contrast, the 2 oligotrophic strains exhibited at most a $25 \%$ reduction in total PBP over $72 \mathrm{~h}$ (Table 2) and the decline occurred at a relatively steady rate during the period. The only pattern similar to Synechococcus sp. WH8018 was in the lack of change in chl concentration. Losses among the various PBPs in the 2 strains were relatively uniform as determined from pigment ratios. In Synechococcus sp. WH8103, AP, PC, and PE declined relative to chl, indicating a loss of functional phycobilisomes relative to chl.

\section{Changes in fluorescence}

In healthy cyanobacteria cells, PBPs pass most of their light energy to PS II. We measured excitation spectra of PS II fluorescence $(680 \mathrm{~nm})$ at intervals before and during the starvation period to assess changes in the composition of the phycobilisomes that remained coupled to PS II. Fluorescence excitation at the $\mathrm{PE}$ maximum relative to the AP maximum should decline if either PE was degraded relative to AP or the energy transfer efficiency between PE and AP (via PC) decreased. This would be noted as a decrease in the ratio of PE:AP fluorescence excitation. This ratio declined significantly in Synechococcus sp. WH8018 after ca 6 h of exposure to nitrogen-free media (Fig 2) and followed closely the kinetics of the loss of PE from the cells as described above. The other 2 strains, however, exhibited little or no chamge in this ratio 
Table 2. Effect of nitrogen starvation on pigment composition and photosynthetic efficiency in 3 Synechococcus spp. strains. PE: phycoerythrin; PC: phycocyanin; AP: allophycocyanin; Chl: chlorophyll. Exponentially growing cells were inoculated in growth media containing $60 \mu \mathrm{M}$ nitrate and sampled at intervals up to $74 \mathrm{~h}$ after the point of nitrate depletion (denoted as time 0). Chl a concentration at the beginning of stationary phase was ca $0.15 \mu \mathrm{g} \mathrm{ml}^{-1}$. Subsamples were analyzed for pigment concentrations or photosynthetic light harvesting efficiency as measured by the slope of the photosynthesis versus irradiance relationship at light limitation. Photosynthesis was measured as gross oxygen evolution using ${ }^{18} \mathrm{O}$ membrane inlet mass spectrometry and normalized to PE concentration

\begin{tabular}{|c|c|c|c|c|c|c|}
\hline Strain & $\begin{array}{l}\text { Time } \\
\text { (h) }\end{array}$ & $\begin{array}{c}\text { Photosynthetic efficiency } \\
\text { (relative) }\end{array}$ & $\begin{array}{c}\mathrm{PE} \\
\left(\text { (fg cell }{ }^{-1}\right)\end{array}$ & $\begin{array}{c}\mathrm{PC} \\
\left(\mathrm{fg} \mathrm{cell}^{-1}\right)\end{array}$ & $\begin{array}{c}\text { AP } \\
\left(\mathrm{fg} \mathrm{cell}^{-1}\right)\end{array}$ & $\begin{array}{c}\text { Chl } \\
\left(\mathrm{fg} \mathrm{cell}^{-1}\right)\end{array}$ \\
\hline \multirow[t]{7}{*}{ WH8018 } & -15 & 0.90 & 33.6 & 3.0 & 2.9 & 3.4 \\
\hline & 1 & 1.00 & 32.5 & 2.7 & 2.7 & 2.9 \\
\hline & 6 & 0.95 & 20.7 & 2.0 & 2.2 & 2.5 \\
\hline & 12 & 0.47 & 17.7 & 1.9 & 2.1 & 2.6 \\
\hline & 24 & 0.31 & 9.1 & 1.6 & 2.1 & 2.6 \\
\hline & 48 & 0.19 & 4.7 & 0.9 & 1.7 & 2.9 \\
\hline & 67 & 0.05 & 4.3 & 0.9 & 1.5 & 2.9 \\
\hline \multirow[t]{7}{*}{ WH7803 } & -16 & 0.91 & 58.8 & 2.8 & 3.0 & 4.5 \\
\hline & 1 & 1.00 & 52.8 & 2.9 & 2.8 & 3.8 \\
\hline & 7 & 1.55 & 49.4 & 2.7 & 2.6 & 3.6 \\
\hline & 12 & 1.26 & 41.8 & 2.3 & 2.1 & 3.8 \\
\hline & 25 & 0.55 & 50.9 & 2.5 & 2.8 & 4.4 \\
\hline & 49 & 0.64 & 46.1 & 2.4 & 2.3 & 4.3 \\
\hline & 73 & 0.13 & 38.6 & 2.2 & 1.8 & 2.9 \\
\hline \multirow[t]{7}{*}{ WH8103 } & -17 & 0.80 & 37.4 & 2.6 & 2.7 & 3.7 \\
\hline & 1 & 1.00 & 32.6 & 2.3 & 2.9 & 3.2 \\
\hline & 8 & 0.71 & 26.9 & 1.9 & 2.3 & 3.0 \\
\hline & 14 & 0.48 & 30.4 & 2.0 & 2.3 & 3.2 \\
\hline & 26 & 0.39 & 30.2 & 1.8 & 2.1 & 3.3 \\
\hline & 50 & 0.59 & 25.4 & 1.4 & 1.5 & 3.7 \\
\hline & 74 & 0.60 & 23.9 & 1.1 & 1.0 & 3.3 \\
\hline
\end{tabular}

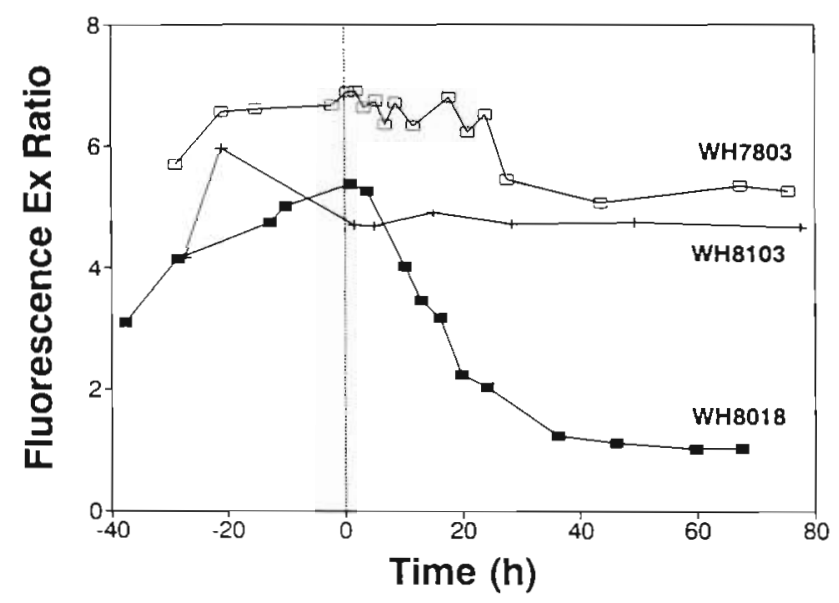

Fig. 2. Time course of the ratio of the PE:AP excitation (Ex) peaks stimulating fluorescence at $680 \mathrm{~nm}$. Excitation spectra of chl $(680 \mathrm{~nm})$ fluorescence were recorded at intervals and the ratio of the peak heights for PE and AP calculated. PE was determined from the urobilin peak for Synechococcus sp. WH8103 and the erythrobilin peak for Synechococcus sp. WH7803 and WH8018. These data reflect changes in the absorption cross-section of membranecoupled phycobilisomes during the entire starvation period (Fig. 2) indicating that PS II-coupled phycobilisomes remained essentially intact.

We also measured fluorescence emission spectra of cells excited by light that was absorbed principally by PE to detect changes in energy coupling between different PBPs and between AP and chl. Whole cell fluorescence emission spectra of exponential phase cells exhibited distinct peaks in the PE (565 to $580 \mathrm{~nm}$ ) and chl $(680 \mathrm{~nm})$ regions of approximately equal magnitude and a broad shoulder at 650 to $660 \mathrm{~nm}$. This shoulder was presumably derived from a combination of both PC and AP fluorescence which exhibit relatively close emission bands in vitro, i.e. $652 \mathrm{~nm}$ for the R-PC II-linker complex and $658 \mathrm{~nm}$ for AP of Synechococcus sp. WH7803 and WH8103 (Ong 1988, Ong \& Glazer 1991). Thus, we were unable to separate fluorescence emission from those 2 PBPs. Synechococcus sp. WH8018 exhibited a large reduction in PE fluorescence relative to chl fluorescence during the first $24 \mathrm{~h}$ (Fig. 3). This was also observed for fluorescence from PC and AP relative to chl (data not shown). The decline in the PE:chl emission ratio correlated 


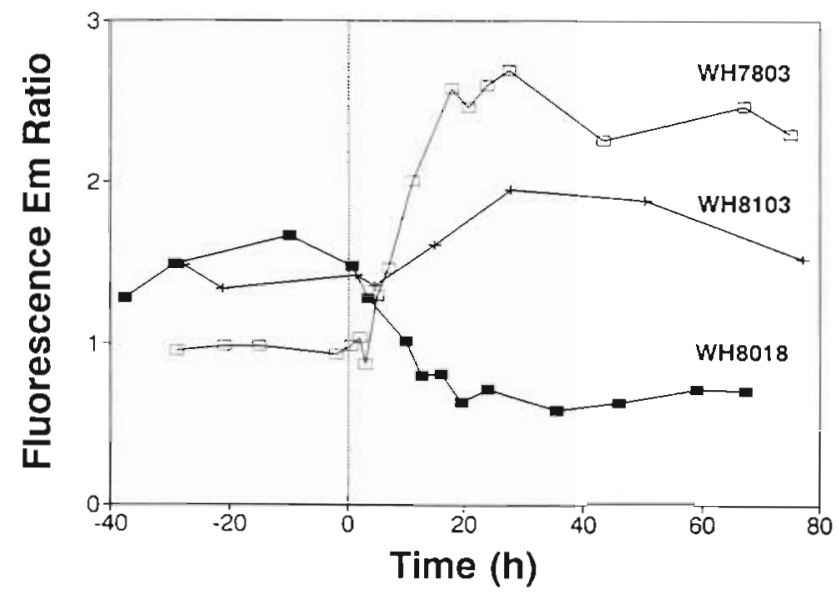

Fig. 3. Time course of the ratio of PE:chl fluorescence emission for cells excited with light absorbed principally by PE (see 'Methods'). Ratios were calculated from the peak emission of PE and chl and time courses refect changes in energy coupling between PE and chl (see text)

temporally with the decline in cellular PE concentration, indicating that the quantum yield of fluorescence by PE relative to chl was constant during the starvation period. By contrast, fluorescence of PE (as well as $\mathrm{PC}$ and AP) from Synechococcus sp. WH8103 and WH7803 rose relative to chl fluorescence during the starvation period (Fig. 3). The increase in the PE:chl emission ratio was greater in Synechococcus sp. WH7803 compared to Synechococcus sp. WH8103 ( 2.5 vs 1.5 times respectively)

\section{DISCUSSION}

Degradation of PBPs during nitrogen starvation is a well documented phenomenon and is generally regarded as typical of cyanobacteria (e.g. Allen \& Hutchison 1980, Wood \& Haselkorn 1980, Yamanaka \& Glazer 1980, Elmorjani \& Herdman 1987, Carr 1988, Allen et al. 1990). We have shown here, however, that a large fraction of cultured marine Synechococcus strains conserve most of their PBP during the first day of nitrogen starvation. Thus, although rapid chlorosis may be a widespread phenomenon among nitrogenstarved cyanobacteria, it is not a general phenomenon

In this study, we were interested in some of the physiological consequences of maintaining PBPs when photosynthetic output (i.e. growth) was reduced. Previous studies have emphasized the role of PBP breakdown in supporting limited growth during the early starvation phase. This relationship is, in fact, supported by the behavior of the oceanic strains, which stopped dividing immediately upon exhaustion of nitrate. The fact that growth stopped abruptly suggests that Synechococcus WH7803 and WH8103 did not contain nitrogen 'reserves' (PBP or other proteins) during exponential phase growth. This may further distinguish the oceanic strains from other cyanobacteria, such as Synechocystis sp. PCC 6308, where it has been suggested that the breakdown of carboxysomes, in addition to PBP, may provide nitrogen compounds for growth during starvation (Duke \& Allen 1990).

Independent of PBP changes, gross oxygen evolution declined in the 3 strains during starvation. Similar declines have been observed for carbon assimilation in Synechococcus sp. WH7803 and WH8018 (Glibert et al. 1986) and a decline in net oxygen evolution in Synechocystis sp. PCC 6308 (Allen et al. 1990), Synechocystis sp. PCC 6803 (Elmorjani \& Herdman 1987) and Spirulina platensis (Boussiba \& Richmond 1980). In the present study, we found that photosynthesis was reduced at the level of PS II activity and non-cyclic electron transport. Because we measured true gross oxygen evolution as well as simultaneous gross uptake rates, we can rule out the possibility that PS II activity was balanced by a high rate of oxygen photoreduction (Mehler reaction), which is rapid under high light intensities (Kana 1992) or when $\mathrm{CO}_{2}$ assimilation is limiting (Miller et al. 1988).

Several mechanisms can cause a decline in PS II activity, including (1) a reduction in absorption cross section caused by a loss of pigmentation or a redistribution of pigmentation (state transition) from PS II to PS I, (2) changes in energy transfer efficiency between the PBPs or between the phycobilisomes and the thylakoid membrane, and/or (3) non-photochemical quenching of chl. Loss of photosynthetic pigmentation (primarily PE) was a significant factor in Synechococcus sp. WH8018, only. But we also found that the PE-specific apparent quantum efficiency also declined in that strain suggesting that there must have been additional factors. We suspect that some form of non-photochemical quenching (energy and/or photoinhibitory) at the level of the thylakoid membrane contributed because there was no increase in fluorescence yield of any of the PBPs in that strain. Nonphotochemical quenching has recently been reported to be manifested in nitrogen-starved Synechocystis sp. PCC6308 (Allen et al. 1990).

In Synechococcus sp. WH7803 and WH8103, PS II activity declined as a result of dissipation mechanisms and not by a loss of pigmentation. Increased fluorescence emission of PE relative to $\mathrm{PC}$ and/or AP indicated that there was some uncoupling of PE from the phycobilisomes. The extent of that uncoupling was minor, however, as evidenced by the small change in the absorption cross section of chl $(680 \mathrm{~nm})$ fluorescence. If we assume that fluorescence of uncoupled PE is 10 to 20 times brighter than fully coupled PE due to 
its longer fluorescence life-time (Yeh et al. 1986), then we can calculate that only 5 to $10 \%$ of the $\mathrm{PE}$ molecules became uncoupled in Synechococcus sp. WH7803. This is consistent with the observed decline in the PE:AP fluorescence excitation ratio. However, the fact that there was a significant decline in the efficiency of $\mathrm{PE}$ in driving photosynthetic oxygen evolution suggests that an additional factor, such as non-photochemical chl quenching, also contributed (Allen et al. 1990).

We can speculate that the advantage afforded Synechococcus sp. WH7803 and WH8103 and other oceanic strains in minimizing the loss of PBPs during nitrogen starvation is the greater speed with which those cells can resume high rates of photosynthesis and growth once nitrogen becomes available. More rapid resumption of growth upon nitrogen replenishment has been observed in Synechococcus sp. WH7803 relative to Synechococcus sp. WH8018 (Glibert et al. 1986, Glibert \& Ray 1990). This may be due to an ability to rapidly reverse the uncoupling and/or quenching while avoiding the cost of resynthesizing new accessory pigments. We believe that such an opportunistic response is advantageous in an oligotrophic oceanic environment where nutrientdeficient surface waters, where Synechococcus predominates, receive pulses of nutrient-rich deep water during wind mixing events that occur on a frequency of days to weeks.

Acknowledgements. We thank John Waterbury for kindly providing the strains used in this study. This work was supported by the National Science Foundation grants OCE8710903 and OCE-9012669 (T.M.K.) and National Science Foundation REU awards (N.L.F. and L.C.F). This is contribution number 2204 from the Center for Environmental and Estuarine Studies.

\section{LITERATURE CITED}

Alberte, R. S., Wood, A. M., Kursar, T A., Guillard, R. R. L. (1984). Novel phycoerythrins in marine Synechococcus spp.: characterization, and evolutionary and ecological implications. Plant Physiol. 75: 732-739

Allen, M. M., Hutchison, F. (1980). Nitrogen limitation and recovery in the cyanobacterium Aphanacapsa 6308. Arch. Microbiol. 128: 1-7

Allen, M. M., Law, A., Evans, E. H. (1990). Control of photosynthesis during nitrogen depletion and recovery in a non-nitrogen-fixing cyanobacterium. Arch. Microbiol. 153: $428-431$

Allen, M. M., Smith, A. J. (1969). Nitrogen chlorosis in bluegreen algae. Arch. Mikrobiol. 69: 114-120

Barlow, R. G., Alberte, R. S. (1987). Photosynthetic characteristics of phycoerythrin-containing marine Synechococcus spp. II. Time course responses of photosynthesis to photoinhibition. Mar. Ecol. Prog. Ser. 39: 191-196

Boussiba, S., Richmond, A. E. (1980). C-phycocyanin as a storage protein in the blue-green alga Spirulina platensis. Arch. Microbiol. 125: 143-147
Carr, N. G. (1988). Nitrogen reserves and dynamic reservoirs in cyanobacteria. In: Rogers, L. J., Gallon, J. R. (eds.) Biochemistry of the algae and cyanobacteria. Clarendon Press, Oxford, p. 13-21

Duke, C. S., Allen, M. M. (1990). Effect of nitrogen starvation on polypeptide composition, ribulose-1,5-bisphosphate carboxylase/oxygenase, and thylakoid carotenoprotein content of Synechocystis sp. strain PCC6308. Plant Physiol. 94: 752-759

Elmorjani, K., Herdman, M. (1987). Metabolic control of phycocyanin degradation in the cyanobacterium Synechocystis PCC 6803: a glucose effect. J. gen. Microbiol. 133: $1685-1694$

Foulds, I. J., Carr, N. G. (1977). A proteolytic enzyme degrading phycocyanin in the cyanobacterium Anabaena cylindrica. FEMS Lett. 2: 117-119

Glibert, P. M., Kana, T M., Olson, R. J., Kirchman, D. L., Alberte, R. S. (1986). Clonal comparisons of growth and photosynthetic responses to nitrogen availability in marine Synechococcus spp. J. exp. mar. Biol. Ecol. 101: 199-208

Glibert, P. M., Ray, R. T. (1990). Different patterns of growth and nitrogen uptake in two clones of marine Synechococcus. Mar. Biol. 107: 273-280

Guillard, R. R. L., Ryther, J. H. (1962). Studies on marine planktonic diatoms. I. Cyclotella nana Hustedt and Detonula confervacea (cleve) Gran. Can. J. Microbiol. 8: $229-239$

Kana, T M. (1992). Relationship between photosynthetic oxygen cycling and carbon assimilation in Synechococcus WH7803 (Cyanophyta). J. Phycol. 28: 304-308

Kursar, T A., Alberte, R. S. (1983). Photosynthetic unit organization in a red alga: relationships between lightharvesting pigments and reaction centers. Plant Physiol. 72: 409-414

Magnus, W., Schindler, B. (1912). Über den Einfluss der Nährsalze auf die Färbung der Oscillarien. Ber. dt. bot. Ges. 30: 314-320

Mantoura, R. F. C., Llewellyn, C. A. (1983). The rapid determination of algal chlorophyll and carotenoid pigments and their breakdown products in natural waters by reversephase high-performance liquid chromatography. Anal. Chim. Acta. 151: 297-314

Miller, A. G. Espie, G. S., Canvin, D. T (1988). Active transport of inorganic carbon increases the rate of $\mathrm{O}_{2}$ photoreduction by the cyanobacterium Synechococcus UTEX 625. Plant Physiol. 88: 6-9

Ong, L. J. (1988). Phycobiliproteins from marine cyanobacteria: bilin distribution and the identification of the terminal acceptor bilin in phycocyanins and phycoerythrins. Ph.D. thesis, Univ. California, Berkeley

Ong, L. J., Glazer, A. N. (1991). Phycoerythrins of marine unicellular cyanobacteria I. Bilin types and locations and energy transfer pathways in Synechococcus spp. phycoexythrins. J. biol. Chem. 266: 9515-9528

Ownby, J. D., Shannahan, M., Hood, E. (1979). Protein synthesis and degradation in Anabaena during nitrogen starvation. J. gen. Microbiol. 110: 255-261

Radmer, R., Ollinger, O. (1980). Measurement of the oxygen cycle: the mass spectrometric analysis of gases dissolved in a liquid phase. Meth. Enzym. 69:547-560

Strickland, J. D. H., Parsons, T R. (1972). A practical handbook of seawater analysis. Bull. Fish. Res. Bd Can. 167

Waterbury, J. B., Watson, S. W., Valois, F. W., Franks, D. G. (1986). Biological and ecological characterization of the marine unicellular cyanobacterium Synechococcus. In: Platt, T., Li, W. K. W. (eds.) Photosynthetic picoplankton. Can. Bull. Fish. Aquat. Sci. 214: 71-120 
Wood, N. B., Haselkorn, R. (1980). Control of phycobiliprotein proteolysis and heterocyst differentiation in Anabaena. $\mathrm{J}$. Bacteriol. 141: 1375-1385

Yamanaka, G., Glazer, A. N. (1980). Dynamic aspects of phycobilisome structure. Phycobilisome turnover during

This article was presented by O. Holm-Hansen, La Jolla, California, USA nitrogen starvation in Synechococcus sp. Arch. Microbiol. 124: $39-47$

Yeh, S. W., Ong, L. J., Glazer, A. N. (1986). Role of phycoerythrin in marine picoplankton Synechococcus spp. Science 234: $1422-1423$

Manuscript first received: June 10, 1992

Revised version accepted: September 24, 1992 